\title{
Metafísica y contradiscurso del método: Hacia una nueva concepción del ser a partir de la óptica de Eduardo Nicol
}

\section{(Metaphysics and counter-method: Toward a new conception of being from the perspective of Eduardo Nicol)}

Roberto Andrés GonZÁLEZ

Recibido: 11 de enero de 2013

Aceptado: 13 de mayo de 2013

\section{Resumen}

En el presente trabajo nos hemos propuesto la factura de una exposición sucinta en torno a la crítica contra la metafísica clásica desde la perspectiva de Eduardo Nicol. Puede decirse que, desde el punto de vista de nuestro autor, la característica básica de la metafísica ha consistido en el soterramiento del ser, es decir, la metafísica clásica, de alguna u otra manera, ha versado acerca de un ser atemporal y oculto. El ocultamiento del ser ha estado íntimamente ligado al olvido del tiempo y al endiosamiento de la razón; justo por esto Nicol se propone ahora una recuperación de la visibilidad del ser en aras de un contradiscurso del método.

Palabras clave: Ser, tiempo, razón, hombre, Nicol.

\begin{abstract}
In this job we have proposed a brief statement the criticism of classical metaphysics from the perspective of Eduardo Nicol. From the standpoint of our author, the basic characteristic of metaphysic has been the burial of being; classical metaphysics in some way or another had focused on an invisible or hidden. The concealment of being has been closely linked to forgetfulness of time and the deification of reason, just that Nicol is now proposed to recovered the visibility of being a counter by the method.
\end{abstract}

Keywords: Being, time, reason, man, Nicol. 


\section{Introducción}

Eduardo Nicol es poseedor de una de las propuestas filosóficas más inquietantes en el contexto contemporáneo, pues el enfoque y trato que hace acerca de los augustos problemas de la metafísica encuentran en éste una salida distinta respecto a la vertida por los filósofos en boga de la posmodernidad. La travesía teórica de nuestro autor discurre por los asuntos capitales de la metafísica; podemos encontrar entre sus preocupaciones filosóficas tópicos tales como: el ser, el tiempo, el hombre, el conocer, el actuar, la ciencia, el logos, etc. En su obra se reúnen tres elementos estilísticos muy difíciles de encontrar, a saber: rigor, profundidad y belleza. La claridad en el texto filosófico, decía nuestro autor, no debe ser cortesía del pensador, sino síntoma de sanidad del pensamiento. Una convicción como estas es curiosa, justamente porque amanece o irrumpe en un contexto filosófico marcado por la crisis. La obra de éste es asequible y se encuentra casi en su totalidad escrita en castellano. Tenemos frente a nosotros un camino filosófico abierto por Nicol el cual no ha terminado de desarrollar todas sus consecuencias filosóficas.

Podría decirse que la biografía de Eduardo José Gregorio Nicol Franciscà está marcada por dos nacimientos en dos tierras distintas; el primer nacimiento, el biológico, ocurre el 13 de diciembre de 1907 en Barcelona España. En 1933 pasa a formar parte del claustro como catedrático de filosofía en el Instituto Salmerón de Barcelona. Su segundo nacimiento, por decirlo de alguna forma, está fechado en 1939, cuando zarpa en buque desde Francia hacia América, producto de la guerra civil española, en el mes de junio llega al puerto de Veracruz México. Nicol entrega, en lo que sigue, toda su vida a la investigación filosófica, desarrollando su obra en la UNAM (Universidad Nacional Autónoma de México). Finalmente, muere el 6 de mayo de 1990, en la ciudad de México a los 82 años de edad. Su vida es, sin duda, el testimonio de una entrega sin reservas a una vocación reflexiva.

Mi esfuerzo -dice Nicol- desde luego, ha sido cuantioso; aunque el resultado (se los confieso) no haya llegado a la altura que yo, en mi temeraria juventud, pude desear. Sí diré que he procurado comunicarles dos cosas: una fe y un método. Una fe en la razón de verdad, y un sentido del método, sin el cual la mente no produce buen discurso' ${ }^{1}$.

Esta fe en la razón de verdad constituye la brega que la filosofía sostiene en contra de una razón de fuerza mayor que hoy más que nunca intenta acrecentar su dominio mundial.

\footnotetext{
1 Nicol, "Palabras de agradecimiento", en, Juliana G., y Lizbeth S., eds. (1990), pp. 29-30, el subrayado es nuestro. En 1987 Nicol cumplió ochenta años de edad, en reconocimiento a su trayectoria académica, los miembros del Seminario de Metafísica de la UNAM (fundado por él en 1946), decidieron ofrecer un homenaje en torno a su filosofía. Los trabajos presentados en este primer homenaje salieron publicados en 1990 en un texto titulado, El ser y la expresión, homenaje a Eduardo Nicol.
} 
El presente trabajo pretende exponer las líneas básicas del contradiscurso del método 2 en Eduardo Nicol. La estructura de nuestra exposición se encuentra trazada en cuatro partes fundamentales ${ }^{3}$. Esta estructuración no es mero capricho, obedece a la lógica de la crítica y prolongación de la metafísica que el autor mismo propone a lo largo de toda su obra. El presente es un trabajo de ontología estricta, toda vez que el ser es quien figura como foco principal de atención. Cabe recordar que la reforma y revolución ${ }^{4}$ de la filosofía que el autor mexicano-catalán logra proponer hacia el final de su obra, se logran a contraflujo, es decir, mediante un contradiscurso, y vienen posibilitadas por dos instancias, a saber, en primer lugar, por la reintegración del ser del hombre con todas sus partes y funciones epistémicas, y en segundo lugar, por la recuperación de la unidad entre el ser y el tiempo. A decir verdad, esto constituye el meollo temático en nuestro presente empeño.

En el presente se ha pretendido un diálogo directo con el autor. Queremos subrayar que no existe, hasta el momento, ningún trabajo publicado que pondere la presencia de un contradiscurso como vía de despliegue en la factura de Nicol. Esta imagen del pensamiento adquiere contorno solo cuando se mira a la obra del autor como un conjunto. La idea del ser, por ejemplo, que se enarbola en esta filosofía, adquiere sentido solo cuando se pone en circulación todo el conjunto, no mirando exclusivamente un lapso episódico del su desarrollo. En este sentido, mencionamos que no ha sido nuestro interés ir pasando revista a las especificidades de la concepción del ser en cada lapso de evolución del pensamiento del autor, sino de construir una la posibilidad de un contradiscurso metafísico, a partir de la ontología de Nicol.

\footnotetext{
2 Queremos aclarar que la noción de "contradiscurso del método" el autor la emplea por primera vez en 1957, aparece como uno de los encabezados en el índice de la primera versión de la Metafísica de la expresión. Si bien resulta cierto que esta noción no vuelve a aparecer como tema en el desarrollo de su obra, resulta obvio, en una visión retrospectiva y de conjunto, que el grueso de su filosofía se erige estrictamente en una suerte de 'contradiscurso'. Justo por esto hemos apostado por este título en el presente empeño: la filosofía de Nicol se desenvuelve como un estricto contradiscurso.

3 Esta cuatro partes son: el divorcio entre el ser y el tiempo; la fragmentación del hombre en sus partes; la recuperación de la unidad del ser del hombre, y la restitución del tiempo al ser. Consideramos que son específicamente estas cuatro fases las que nos permitirán atisbar, grosso modo, los términos fundamentales de la crítica y la enmienda de la metafísica en nuestro autor.

4 Nicol se propone dos augustas operaciones, distintas pero hilvanadas: una reforma y una revolución en la filosofía. La reforma estaría caracterizada por la devolución del principio vital de la filosofía (ethos vocacional) como motor existencial y principio de unidad entre los diferentes sistemas de filosofía; Cfr. Reforma de la filosofia, (1980), § 1. A su vez la revolución en la filosofía se encuentra enderezada hacia el trastocamiento de las teorías: marcar un nuevo punto de partida para la metafísica del porvenir; Cfr. Crítica de la razón simbólica, (1982), § 1.
} 


\section{Contenido}

El pensamiento de Eduardo Nicol se abre paso a través de una augusta crítica enderezada hacia el centro mismo de la tradición filosófica. Los dos problemas fundamentales sobre los cuales discurre la obra de nuestro autor son, por un lado, la preocupación por el ser (ontología) y, por otro, la pregunta que interroga por el ser del hombre (antropología). Cabe señalar que el empeño realizado por nuestro autor pretende, pese a todo, la facturación de un sistema filosófico. De hecho, estas dos preocupaciones siempre caminan, en su filosofía, engarzadas sistemáticamente. Desde luego, aquí debemos ponderar la noción misma de sistema, ya que el sistema en éste no se concibe como un conjunto cerrado de ideas; la realidad misma es ya un sistema, en cuanto que constituye un todo. La filosofía, al estar enderezada hacia la realidad, tiene por principio que articularse como sistema, es decir, tiene que construirse como un sistema de juicios articulados entre sí: "Los sistemático -dice Nicol- es precisamente la secuencia del desenvolvimiento, a partir de unas nociones primitivas o principales: la comunidad de itinerario"5; sin esta figura la filosofía resultaría una secuencia desarticulada y sin consecuencia. La noción de sistema que se desarrolla en esta obra se encuentra matizada por el entrecruzamiento de dos elementos clave, a saber, el devenir del conocimiento y la comunidad de teorías, justo por esto el sistema es a un mismo tiempo comunidad y continuidad de itinerario. Esto es, el sistema del conocimiento que propone nuestro autor precisa el concurso de los demás puntos de vista, este sistema está constituido por un concierto de voces en activo diálogo y renovación permanente.

La crítica, pues, orquestada por Nicol toma cuerpo a partir del desencanto que le ocasionan los diferentes planteamientos de la metafísica clásica y contemporánea en torno al ser y al hombre. La primera característica dominante que nuestro autor descubre en toda la tradición, desde Parménides hasta Heidegger, es una eminente dislocación ontológica, es decir, para nuestro autor, desde Parménides la filosofía ha venido reiterando, bajo diferentes figuras, la concepción de un ser inamovible y escatológico ${ }^{6}$. La tradición en este sentido podría entenderse como un reiterado anhelo por alcanzar el ser desde el claro de esta dislocación ontológica.

Esta escatología ha marcado un programa de trabajo para el decurso de la metafísica desde sus inicios, el cual se ha caracterizado por suponer, entre otras cosas, que existen dos realidades adjuntas, la una sería objeto de la mera opinión, mientras

\footnotetext{
5 Nicol (1989), p. 18

6 Para nuestro autor, Parménides representa la primera pieza desde donde se puede rastrear la intemporalidad del ser: esta intemporalidad constituye la causa del soterramiento ontológico. La crítica, en este sentido, se enderezará contra esta intemporalidad. Cabe reconocer que desde la publicación de Historicismo y existencialismo (1950), Nicol reconoce la necesidad de devolverle el tiempo al ser, justo por esto el subtítulo de esta obra rezaba: "la temporalidad del ser y la razón". Esta obra representaba los prolegómenos a Metafísica de la expresión (1957).
} 
que la otra sería objeto de la ciencia primera. El mundo de la opinión se correspondería con la realidad perceptible, esta realidad perceptible sería la versión degradada del ser; sería, como dice Platón, una copia del ser, pero de ninguna manera el ser tal como es en sí. El objeto de la opinión es el devenir y la pluralidad de las cosas: Parménides 7 ya adjetivaba de "bicéfalos" 8 a los hombres que caminan por la vida ateniéndose únicamente al dato del devenir y la pluralidad. Les llama bicéfalos porque todo juicio enderezado hacia el devenir siempre será provisional: lo que deviene, decía, no puede ser objeto de una fe verdadera. Parménides instala la filosofía en la ruta de la verdad inamovible y el ser inmutable. La inmutabilidad es una nota que conviene exclusivamente al ser; así también, la proposición de esta verdad deberá ser expresada en términos inamovibles, digamos que esta verdad debe ser una suerte de axioma universal y necesario. Desde luego, el eleata no niega el devenir, como tampoco niega la pluralidad de las cosas, lo que sí acota tajantemente es la posibilidad de fundar sobre el claro de éstos la proposición de la verdad. El "Poema" de Parménides nos ofrece una arquitectura trazada por el entrecruzamiento de dos caminos, uno es el camino del error; cabe mencionar que en este camino es inevitable justamente porque todos nosotros hemos tenido que nacer en medio de una cultura plagada de prejuicios y verdades a medias. Digamos que este primer camino, epistemológicamente hablando, es el horizonte del devenir y la pluralidad, aquí es donde el grueso de los mortales permanece anclado, ateniéndose a lo que cambia construyendo proposiciones pasajeras y sin necesidad universal, Parménides le llama a esta ruta "el camino trillado por los hombres"9, del cual el buscador de la verdad tiene que apartarse.

Junto a esta ruta del conocimiento vulgar se halla la ruta de la verdad, esta segunda ruta se encuentra bien alejada de la primera, y a diferencia de aquélla esta última precisa el concurso de una decisión o elección, pues como dice el eleata "no es un hado infausto el que te movió a recorrer este camino [de la verdad]" 10 , sino tu libre decisión.

Ahora bien, el empeño de Parménides por concebir el ser como inmutable, evidentemente, conducen su pensamiento hacia una eminente dislocación entre el objeto del camino del error y el anhelo del camino de la verdad. De esta manera, la apariencia sería la nota que distingue esa forma de ser que es advenediza cuyo conoci-

\footnotetext{
${ }^{7}$ Los dos pasajes donde Nicol discurre de una manera sostenida contra la filosofía de Parménides se encuentran en La idea del hombre (1947), en el capítulo quinto titulado "La unidad como punto de partida"; y en el capítulo cuarto de la Metafísica de la expresión (1957), titulado "La crisis de la metafísica. Etiología y diagnóstico".

8 Parménides B VI 5, tomado según la traducción de J. Antonio Míguez, Parménides, Zenón y Meliso, (Escuela de Elea), Bs. As., Aguilar, pp. 45-57. Cotejada con, Parménides en, Los Filósofos presocráticos I, Madrid, Biblioteca Clásica Gredos, pp. 474-484.

9 Parménides B I 27.

10 Parménides B I 26.
} 
miento no pasa de ser mera opinión, la razón tiene que desdeñarla, pues no merece mayor atención: lo advenedizo y cambiante no puede ser objeto de una fe verdadera. Por el contrario, el ser es inmóvil, esto es, carece de origen y de fin: es necesario que sea, es decir, siempre ha sido, su necesidad ontológica se corresponde con su eternidad. La necesidad es una nota exclusiva del ser, en virtud de que no posee una datación; justo aquí es donde se fincan las bases para la consecución de la verdad inmutable, la cual declara que "el ser es y el no ser no es"11. Es necesario que el ser sea, porque el no ser no es. Es decir, el ser es en virtud de su propia necesidad, y no porque el no ser no sea; el ser no debe el ser al no ser, sino que es en virtud de su propia necesidad. Aquí cabe subrayar que el camino de la verdad, en cierta manera, constituye una segunda mirada. En este sentido, esta escarpada hacia la verdad precisa una suerte de epojé, se necesita poner entre paréntesis los datos de los sentidos y los prejuicios del conocimiento vulgar para que en adelante el buscador de la verdad incursione animado por las fuerzas del puro pensamiento.

Consideramos que la primera epojé en la historia de la filosofía, sin duda, fue puesta en marcha por el pensamiento de Parménides. Esto puede entenderse desde el momento mismo en que el eleata distingue los dos caminos y cuando le dice al buscador que es necesario que diferencie entre uno y otro camino, porque es indispensable que sepa distinguir la vía en donde todo es confusión, para dejarla atrás, y sepa encaminarse por la ruta de la verdad. Parménides dice: "es necesario que conozcas toda mi revelación, y que se halle a tu alcance el intrépido corazón de la verdad..., tanto como la opinión de los mortales, que no encierran creencia verdadera"12. Parménides le prohíbe al buscador que enderece su exploración por el primer camino, ya que por ahí no puede accederse a la verdad. Es decir, el eleata mediante este argumento está plateando la necesidad metodológica de la epojé. Porque es necesario que el explorador abandone el primer camino, o sea, que ponga entre paréntesis sus datos, los datos del conocimiento natural, y que mediante esa suspensión se enderece hacia la ruta de la verdad. Cabe mencionar que esta epojé es lo que marca la punta de la crítica de Nicol a la tradición.

La filosofía, dice nuestro autor catalán, puede entenderse como una prolongada epojé. "Ninguna filosofía en la historia ha producido una escisión tan cortante de la unidad y continuidad del conocimiento: la verdad es el ser, la opinión es el no ser, no hay entre las dos una mediación gradual"13. La tradición ha ido matizando epocal-

\footnotetext{
11 Parménides B II 3.

12 Parménides B I 28-30.

13 Nicol (2008), p. 86. La primera edición de la nueva versión de la Metafísica de la expresión sale a la luz en 1974, esta es, como dice el autor, una versión refundida de la que apareció en 1957. En esta segunda versión fueron suprimidos el Prólogo y el capítulo segundo, por lo demás la obra conserva su estructura y secuencia. La última reimpresión de la obra publicada en 1974 sale en 2008, es la que hemos empleado en nuestro presente empeño.
} 
mente esta epojé instaurada desde la filosofía griega; la tradición ha discurrido en pos de un ser cuasi inasequible, así también, ha ido en pos de una verdad inamovible.

Con Parménides y Platón quedan echadas las bases del programa de la metafísica del porvenir. La presunción de un ser inmutable se corresponde, desde luego, con el anhelo de una verdad también inamovible. En contraste, la evidencia de una realidad evanescente resulta un dato que ahí está patente ante todos pero que la metafísica no sabe explicar. Esta ha sido una paradoja que se ha arrastrado a lo largo de la tradición. "Después de Parménides quedaba planteado el problema racional de la compatibilidad entre dos evidencias. La física y la metafísica tenían que resolver la presunta oposición entre pluralidad y unidad, entre devenir y ser" 14 . Digamos que la inmutabilidad como nota del ser se configura como la verdad, muy a pesar del dato del devenir de lo real. El costo mayor que se pudo grabar al intento parmenideo por identificar el ser como inmutable, no es tanto que se erija en objeto de la razón pura, sino más bien que por causa de esto el ser desaparece del horizonte visual. Con el divorcio entre el ser y el tiempo comienza la era del ocultamiento del ser o la era del ser soterrado. Esto es, la metafísica ha corrido tras la huella de un ser que de suyo se encuentra ausente. La inmutabilidad trajo como consecuencia la invisibilidad del ser. Y, a decir verdad, este ha sido el precio más caro que ha tenido que pagar la metafísica, a saber, lidiar con un ser invisible. Podría decirse que desde que el ser se divorcia del tiempo, éste ha sido cuasi inasequible, se diría que la razón no sólo tuvo que construir un método, sino que más aun, tuvo que inventar el ser mismo y proveerle las pautas para su existencia. Abonando un poco al respecto, ahí está por ejemplo el principio de identidad formulado por Aristóteles en donde dice que "es imposible que lo mismo se dé y no se dé en lo mismo a la vez y en el mismo sentido"15. Recordemos que para el estagirita este postulado constituía el principio que garantizaba el menor dejo de error. Sin embargo, lo que aquí encontramos es la preeminencia de la razón sobre el ser mismo, ya que es la razón quien le está marcando la pauta no solo al conocimiento del ser, sino también a la existencia del ser: el ser puede ser posible en cuanto que puede ser pensado, amén de que no puede ser y no ser al mismo tiempo.

Hay que remarcar que a Nicol le preocupa en gran manera este entrecruzamiento: el contraste entre la evidencia del devenir y la necesidad del pensamiento del ser. Esto es, ¿de qué manera pueden cohabitar en el hombre la evidencia de la experiencia inmediata del devenir y la evidencia racional de la necesidad lógica de un axioma metafísico como el que enuncia Aristóteles? Esto, en verdad, es una suerte de escándalo. El autor catalán nos dice que la filosofía "tiene que resolver el problema de las dos evidencias incompatibles: la de una experiencia inmediata y la de un

\footnotetext{
14 Nicol (2008), p. 85.

15 Aristóteles. Metafisica, IV 1005b 20.
} 
axioma racional"16. ¿Cómo se puede conciliar el dato del devenir que la experiencia común nos propicia, con la necesidad de un axioma como el de no contradicción? Esta es una de las consignas que asume Nicol. Sobre esto volveremos más adelante.

Hay que agregar que esta paradoja que subyace en el seno de la metafísica se encuentra a su vez íntimamente ligada a la desarticulación o fragmentación del hombre17, llevada a cabo por la filosofía en la época clásica griega. Ya en Parménides se echan de ver dos niveles del conocimiento, los cuales se corresponderían con el mismo número de capacidades epistémicas. El hombre estaría dividido en dos partes, mismas que se corresponderían con cierto objeto de atención: la percepción estaría enderezada hacia el devenir; mientras que el pensamiento hacia lo inamovible. Si en el hombre existen dos capacidades epistémicas, resultará obvio, que éstas se correspondan con el mismo número de grados del ser: hay menos ser en la sombra reflejada que en el objeto de donde emana la sombra. Así también, el conocimiento de la sombra será menos verdadero que aquel que versa sobre el ser en sí.

Hay que reconocer que Platón es el gran maestro de la disyunción ontológica. De hecho, la estructura de su pensamiento presenta siempre este conato de respectividad. Cada forma del ser se encuentra referida a otra adyacente. Así, la apariencia se entiende en relación al ser en sí, siendo que la apariencia es una manera de ser en otro, es una manera degradada de ser. Nuestra sensibilidad sería conveniente con la forma de ser aparente, pero en ninguna manera con el ser, por esto el conocimiento de los sentidos siempre será una suerte de seudoconocimiento. Malos testigos son los sentidos para la verdad. La verdad sería objeto solo de la razón. En este sentido, el alma sería lo que define al hombre, y ésta se encuentra encarcelada en las murallas del cuerpo. Platón concibe al cuerpo como aquello que ata al hombre a la tierra y lo mantiene inmerso en el mundo de las apariencias; por el contrario, el alma se encuentra enderezada hacia el mundo de las ideas. El hombre, para el autor ateniense, está compuesto por dos partes irreductibles entre sí, la sensibilidad y la razón; la primera, se endereza hacia las apariencias; mientras que la razón está ten-

16 Nicol (2003), p. 50. La primera edición de La idea del hombre sale en 1947, publicada por la Editorial Stylo. En 2004 sale una edición facsimilar publicada por Editorial Herder. Sin embargo, la que se conoce como nueva versión de La idea del hombre sale en 1977, publicada por el Fondo de Cultura Económica, esta nueva edición es una obra enteramente distinta de la de 1947. La última edición de la publicada en 1977 sale en 2003, es justo la que hemos empleado en nuestro presente estudio.

17 La primera huella acerca de la preocupación por la integración del hombre en sus partes, Nicol la registra en la publicación de su primer libro, Psicología de las situaciones vitales (1941), ahí ya mencionaba que el ser humano es una unidad indesglosable: la psique no opera aisladamente del cuerpo, y viceversa. El hombre aparece como un todo indesglosable. Cfr. Nicol (1989), p. 25. Sobre esto se insistirá más adelante. 
dida hacia la verdad. La verdad, decía Platón, es lo que no cambia y siempre es, mientras que lo que cambia no puede ser verdad, es objeto de la mera opinión: "¿Qué es lo que siempre es y no deviene y qué, lo que deviene continuamente, pero nunca es? Uno puede ser comprendido por la razón, el ser siempre inmutable; el otro es opinable mediante la percepción sensible"18. En la filosofía del autor ateniense se ha naturalizado la dislocación del hombre en sus partes y su respectiva correspondencia para con cierta forma del conocimiento.

Ahora bien, Nicol piensa que esta dislocación del hombre en sus facultades psicológicas y partes antropológicas se corresponde, a su vez, con el divorcio entre el ser y el tiempo. Es decir, si la filosofía nos ofrece una visón dislocada de la realidad, es porque el hombre se concibe a sí mismo ya como dislocado. Esto se puede atestiguar en toda la obra de Platón: la idea de los dos mundos se corresponde con la idea del hombre concebido como la unión de dos sustancias, la una adventicia (cuerpo) y la otra inmortal (alma), unión que por cierto la filosofía nunca ha podido explicar.

Eduardo Nicol piensa que el camino para el porvenir de la filosofía contemporánea se traza justamente en un contradiscurso del método. ¿Qué significa contradiscurso en filosofía? Desde luego, esta noción está más emparentada con la hazaña de Descartes, cuya obra principal lleva por título El discurso del método ${ }^{19}$. Sin embargo, el recorrido que traza el autor francés en este trabajo resulta tan emblemático, al grado tal que retrata el punto en donde coinciden los diferentes discursos del método en la tradición. Cada discurso del método ha partido de la convicción de hallar una evidencia: el suelo firme para la construcción del conocimiento, este suelo deberá ser inamovible (inconcuso) y ulterior, cual puerto de llegada. En suma, todos los discursos del método parten hacia la búsqueda de una evidencia primera que sirve de fundamento angular al edificio del conocimiento 20 . No obstante, en aras de este compromiso la razón misma ha terminado por proveer de realidad el fundamento que inicialmente motivó su búsqueda metódica. Nicol dice que el común denominador en los discursos del método ha sido el endiosamiento de la razón. Y esto puede verse desde Parménides, pasando por Platón, en Descartes hasta la filosofía del siglo XX.

El contradiscurso, orquestado por Nicol, pretende desandar la vereda recorrida por la metafísica clásica. El contradiscurso es en sí mismo una crítica a través de la cual el autor pretende anclar más sus raíces en la tradición. El discurso de Descartes comienza dudando ${ }^{21}$, es decir, comenzaba poniendo entre paréntesis los datos de los sentidos, dudando de todo su entorno, posteriormente clasifica los problemas y muy

\footnotetext{
18 Patón. Timeo, 28b.

19 Cfr. Descartes (2001), pp. 50ss.

$20 \mathrm{Nicol}$ (2001B), pp.153ss.

21 Descartes (1982), p. 47.
} 
ulteriormente deducía la evidencia. Queremos resaltar esto último, a saber, el hallazgo de la evidencia en Descartes acontecía luego de la puesta en marcha de unas maniobras metodológicas, la evidencia acontecía ulteriormente. En este sentido, algo recurrente en los discursos del método es la convicción de que el ser siempre es una instancia ulterior de llegada, es decir, el ser siempre está separado, y en consecuencia una de las consignas de la filosofía ha consistido en darse a la tarea metódica de buscarlo, inclusive más allá de las estrellas, y por supuesto más allá de la de los datos de los sentidos. El primer paso partía de la duda. De hecho el método estaría enderezado hacia la erradicación o superación de la duda y el error. Éste sería una especie de filtro mediante el cual el error pudiese transformarse en evidencia. Las reglas del método marcan la ruta ideal para llegar a la verdad.

Por su parte, el contradiscurso enarbolado por Nicol, no es un tema, sino una manera de orquestar el gesto filosófico 22 . Hay que subrayar que nuestro autor, mexicano-catalán, sigue poseyendo la plena convicción de que el conocimiento verdadero debe fundarse en alguna suerte de evidencia, esta evidencia debe ser también inamovible, y para lograr su objetivo el autor de Los principios de la ciencia decide tomar otro atajo al proferido por la epojé. Es decir, la primera confección del contradiscurso consiste en poner entre paréntesis precisamente la epojé, y atenerse al dato de la realidad.

Nuestro autor considera que la tradición ha llegado a un momento crítico sin paralelo en nuestro tiempo, ha agotado su potencial que podía desarrollar por este camino que emprendió cuando asumió como panacea la idea del ser inmutable. Como ya se dijo, un ser inmutable es a la vez un ser invisible. El proyecto de la metafísica clásica comienza justo con el divorcio entre el ser y el tiempo. A la vez, esta dislocación trae aparejada otro desdoblamiento que la filosofía no ha podido explicar ni cerrar, a saber, la coexistencia de un alma inmortal en un cuerpo mortal. La filosofía ha venido arrastrando la incompatibilidad entre la eternidad del ser y el dato del dinamismo de la realidad. El contradiscurso del método, entonces, tendría como consigna revertir semejante paradoja, es decir, tendría como propósito restaurar, por un lado, la unidad entre el ser y el tiempo, y por otro, restablecer la unión de todas las facultades psicológicas en el ser del hombre. En este sentido, una de las consignas de la nueva metafísica consiste en restituir la unidad (indesglosable) del ser der hombre23. Dice Nicol que el hombre siempre es uno en cada situación: es implícitamente sentiente e inteligente: no es sentiente unas veces y otras solo inteligente, siempre funciona integralmente: la aistesis y el nous caminan indesglosables en cada momento de la existencia. Sin embargo, con esta reintegración,

\footnotetext{
22 Insistimos, el contradiscurso en Nicol no es propiamente un tema, desde nuestro punto de vista, constituye más bien la figura que asume su pensamiento al tener que remar a contracorriente, colocando el ser no como instancia ulterior de llegada, sino como el punto de partida.

23 Cfr. Nicol (1981), §1.
} 
resulta que la unidad en el hombre no es ulterior, antes bien está dada desde el inicio, por la simple razón de que la inteligencia está plenamente en la percepción, y viceversa. Nicol dice: "la unidad está dada ya en la experiencia inmediata, y no ha de ser resultado de una recomposición hipotética" 24 , constituye una unidad que no puede desarticularse. La percepción constituye, sin duda, el nivel más rudimentario del conocimiento, no obstante, no por esto deja de estar articulada del resto de las funciones epistemológicas del hombre; la percepción es ya una operación sumamente compleja, "de suerte que-Dice Nicol-la llamada percepción sensible de un objeto es en realidad una operación compleja, para la cual se requiere el concurso integrado de facultades que la psicología solía considerar como distintas y separadas" 25 . En suma, no hay ninguna función psíquica que opere aisladamente de las demás, el ser humano opera integralmente en cada momento. "No bastaba integrar en unidad las funciones psíquicas que la psicología consideraba tradicionalmente de manera aislada; era necesario integrar la presunta unidad constituida por la psique entera con el factor somático, para obtener al hombre completo"26. Hay que decir que la restitución de la unidad del hombre con todas sus partes y funciones psicológicas figura como un elemento indispensable en la recuperación temática de la visibilidad del ser. En este sentido, semejante restitución antropológica aparece como uno de los momentos clave del contradiscurso del método en Nicol27.

Así pues, el autor nos dibuja bajo los siguientes términos el programa del contradiscurso del método: "si conseguimos por fin restablecer en metafísica la unidad y eternidad del ser, sin excluir el dinamismo" 28 , entonces estaremos encontrando otro derrotero por donde pueda darse salida a la crisis actual de la metafísica. Es decir, para superar la paradoja antes mencionada, el camino del contradiscurso tendrá que comenzar por resarcir la dislocación entre el ser y el tiempo: restituirle el tiempo al ser. Nicol encuentra que no existe ningún inconveniente entre el dato del dinamismo de la realidad y la permanencia del ser. El ser es al mismo tiempo permanente y dinámico, y para afianzar su permanencia no precisa desentenderse del tiempo, de hecho, lo permanente refulge en el cambio, a la vez que el cambio reafirma la permanencia del ser. Devolverle el tiempo al ser implica volver a poner al ser en un horizonte visual. El devenir es ante todo un dato apreciado por la percepción sensible, el devenir es una evidencia que no ha sido inventada por la razón. El contradiscurso, en este sentido, tiene la consigna de atenerse a lo dado, es así que no puede poner entre paréntesis el dato del dinamismo, en virtud de que el devenir

\footnotetext{
24 Nicol (1989), p. 68.

$25 \mathrm{Nicol}(2008)$, p. 143.

26 Nicol (1989), p. 17.

27 Para un estudio más exhaustivo en torno a la recuperación de la unidad del ser del hombre en sus partes a partir de Nicol, puede consultarse el libro: González, Roberto (2010A), pp. 59ss.

28 Nicol (2008), p. 90.
} 
sería el primer dato con el que nos aparece el ser. Porque si se trata de restituir el tiempo al ser, resulta obvio que tenemos que reconocer que en el devenir, y no más allá de éste, está justamente el ser. Si esto es posible, entonces se habrá superado la necesidad de la epojé como primera estrategia metodológica para acceder al ser.

Nicol comienza distinguiendo la noción de mismidad y la noción de identidad. La tradición ha querido entender al ser como idéntico. Hay que reconocer que en efecto el ser es algo permanente: "El ser es esa misma firmeza que requerimos para pensar y ser"29. El ser siempre está ahí, no cambia, puesto que no ha venido a ser y tampoco dejará de ser (no es un ser entre los demás entes). Es el ente (finito) quien se encuentra determinado y en proceso de cambio, pero el ente no es aparte del ser. El ente acontece en el ser, aunque también resulta cierto que no puede haber ser más allá del ente, puesto que el ser es uno: no hay un ser oculto y otro ser visible. Aunque aquí cabe aclarar que si bien el ente se da en el ser, también resulta cierto que el ser no se agota en un ente determinado. El ser es quien hace ser al ente, y en aquél este último viene a ser y también dejará de ser. Solo en el proceso del tiempo el ente gana unidad entitativa, es decir, solo en el proceso de sus transformaciones un ente adquiere mismidad. La mismidad es una cualidad que se adquiere en un proceso. El ente no es idéntico, logra ser el mismo, porque se transforma. "En verdad, si no cambiara no se advertiría que es el mismo, en sí mismo"30. Lo cierto es que el ser no se encuentra más allá del ente, esta dislocación fue inventada artificialmente por la razón.

El devenir es el primer dato que aparece ante el hombre, cuya evidencia no implica una devaluación ontológica. La mismidad es un fenómeno que puede apreciarse en todo momento y en todas las cosas, y que la caducidad de éstas no inhabilita la eminencia del ser. El ser constituye el horizonte ontológico donde los entes advienen. El hombre debe aprender a mirar el ser en el acontecimiento del ente. Cada ente, lo primero que patentiza es el hecho de la existencia, es decir, cada cosa patentiza el simple hecho de que hay ser. Este hecho es permanente y no pierde vigencia con el devenir de las épocas. Todos los entes son relativos por cuanto que se encuentran volcados unos contra otros, pero lo que no es relativo es el hecho del ser. Nicol dice: "Todo lo que existe es, en efecto, relativo; pero el hecho de que hay Ser no es relativo a nada: es condición de posibilidad de toda relación"31. El devenir no oculta el ser, toda vez que el ser refulge en cada movimiento en el ente. Esta concepción es viable por cuanto que no puede haber ser sino precisamente en el ser, es decir, el ente no puede ser sino en el ser, y a su vez el ser no puede ser más allá

\footnotetext{
29 Nicol (2008), p. 94.

$30 \mathrm{Nicol}$ (2008), p. 95.

31 Nicol (2001A), p. 366. En 1965 sale a la luz el monumental texto de Nicol titulado Los principios de la ciencia, las siguientes reimpresiones son versiones intactas de esta primera. En 2001 sale la quinta reimpresión del texto en cuestión, ésta es la que hemos utilizado en nuestro presente estudio.
} 
del ente. Sólo tiene que aclararse que el ser no es reductible a un ente, y que un ente no agota el ser en su totalidad. Se diría que en esta ontología, el ente es justamente la carta de presentación del ser: "solo podemos ver el ser en lo que existe"32. El ente se explica por el ser, y a la vez, el ser es patentado por el ente. Uno conduce al otro y viceversa. El ente no es mera señal para acceder al ser, no, sino que el ser está en el ente. Y para mostrar esto Nicol tiene que enfatizar que el ser no es una creación de teoría, sino más bien un hecho, es decir, está previamente a toda configuración teórica. Es así que cada movimiento orquestado por el ente pone en circulación el dato de que hay ser.

Nicol dirá que siempre hay, y ha habido, ser. La presunción de la razón filosófica es la que ocasionó su ocultamiento. No obstante, pese a todas las maquinaciones teóricas, siempre hay ser. El hecho de que hay ser no pierde vigencia, justo por esto puede retenerse la idea de que, en efecto, el ser es permanente, pues pase lo que pase siempre hay ser. El ser no desaparece con el ocaso de un ente, tampoco con la emergencia de una cosa. El ser no ha venido a ser y no deja de ser.

El tiempo vuelca el ser en presencia. La recuperación del tiempo permite restituir al ser el adjetivo de presencia. "La presencia acontece en el tiempo a la vez que el tiempo trastoca lo que es en presencia. O mejor dicho, justamente porque lo que es deviene como tiempo es que lo existente puede acentuarse también como presencia"33. Lo que se diluye en el tiempo no mengua un solo ápice de realidad a lo que es, por el contrario, se trata de la justa coincidencia del devenir en lo que es para acentuar la omnitud de la presencia. Podría decirse que tiempo y presencia constituyen los atributos preeminentes del ser en Nicol. Ahora el ser puede pensarse como tiempo, precisamente porque el tiempo del ser resulta asequible a la experiencia común, la cual se desarrolla en lo abierto de la multiplicidad de texturas y formas de la realidad. En el tiempo sobrevienen las múltiples diferenciaciones del ser.

Podría decirse que por el tiempo el ser se torna múltiple en sus diferencias específicas, no obstante, por el tiempo el ser también gana unidad. El ser no podría ser uno si es que no permaneciera unido en sí desde su mismo centro. La pluralidad de sus diferencias no contraviene la unidad del ser, por el contrario, ahora que se ha visto que el ser es el horizonte en el que toda existencia particular viene a ser, y que cada ente remite al ser, entonces por muy variada que sea la multiplicidad de las cosas no demerita la unidad del ser. Puede decirse que el tiempo es la razón de la unidad y la visibilidad del ser. El devenir entrelaza las declinaciones múltiples del ser, inhibiendo cualquier propensión hacia un dislocamiento ontológico. El concur-

\footnotetext{
32 Nicol, (2001A), p. 365.

33 González, R. (2010B), p. 287. En 2007 se cumplió el centenario del nacimiento de Eduardo Nicol, por este motivo la UNAM organizó un homenaje en torno a la obra de éste. Los trabajos presentados se encuentran recogidos en, Ricardo Horneffer, Eduardo Nicol (1907-2007), homenaje, publicado por la UNAM, 2009.34 Nicol (2003), p. 58.
} 
so del tiempo exige que esta reunión sea reiterada por el entrelazamiento de lo que está en movimiento, y justo por el tiempo, el ser adquiere una actualidad permanente. Y, en verdad, la misma noción de presencia puede entenderse como actualidad permanente. Esta actualidad permanente es lo que impide el soterramiento del ser. Dice Nicol “...presencia; no es mero relato, sino re-actualización..., el ser pasado no es sino una versión de su propia mismidad"34. La presencia requiere de manera indispensable el concurso de lo diferido en el cambio. Siendo que los entes al transformarse y diferenciarse se engarzan entre sí, la unidad del ser adquiere contorno, al tiempo que por el dato del devenir la forma del cambio refulge justamente como permanente. El concurso del tiempo, aparte de permitir la explicación de la unidad del ser, permite también explicar lo permanente. Siendo que para nuestro autor, lo permanente también es el cambio mismo, o más bien la forma del cambio: "Lo permanente es la forma del cambio" 35 . En suma, el tiempo se erige como principio de unidad de lo que es y como principio de visibilidad del ser.

Como puede notarse, en Nicol se lleva a cabo un trastocamiento en el programa de la filosofía ${ }^{36}$, pues para éste resulta que no es ya función de la razón encontrar los principios del conocimiento, sino más bien le corresponde reconocer "que la metafísica no se encuentra ahora en situación de empezar de nuevo sin una base de principios" 37 , no es posible partir de cero, el conocimiento no está parado en la nada. A la razón no le compete dotar de fundamento a la ciencia; la primera evidencia que la nueva metafísica precisa no puede ser un producto de la razón, a esta última le compete más bien reconocer y partir de la presencia del ser. Hay que señalar que la primera evidencia, desde esta óptica, no es de razón, sino de experiencia: "Es el hombre común quien la percibe. Hace de ella una experiencia directa"38. A la razón le corresponde atenerse sin más a esta evidencia. En este sentido, el orden de las reglas de método también queda trastocado: "la primera regla de este método impone la obligación de atenerse rigurosa y estrictamente a lo dado"39. La evidencia no queda pospuesta para un momento posterior en las fases del método, por el contrario, se constituye en el punto de partida de toda duda y de toda investigación.

\footnotetext{
34 Nicol (2003), p. 58.

35 Nicol (2003), p. 17.

36 Para un estudio más exhaustivo en torno al trastrocamiento del programa de la metafísica a partir de la óptica de Nicol, puede consultarse el libro: González, Roberto Andrés (coord.) (2011), pp. 259ss. En este texto se desarrolla de una manera más sostenida el sentido de este nuevo camino esbozado por Nicol para la metafísica.

37 Nicol (2008), p. 91.

38 Nicol (1998), p. 67. En 1961, Nicol publica la primera edición de El problema de la filosofía hispánica, uno de los méritos de este texto consiste justamente en que aquí se esboza el doble aspecto de la filosofía, como sabiduría y como ciencia sin más; amén de que en el mismo hace una ingeniosa reflexión sobre las aspectos más dominantes en el quehacer de la filosofía hispánica: engloba en este término al quehacer filosófico en España y Latinoamérica. La segunda edición sale en 1998.

39 Nicol (2008), p. 120.
} 
El contradiscurso de $\mathrm{Nico}^{40}$ se ve coronado cuando éste cae en la cuenta que de hecho no se necesita de ningún método para acceder al ser. Puesto que en el ser ya estamos desde luego y desde siempre. Participamos del ser cada vez que hablamos. El ser no está aparte, ni constituye el anhelo de la otra orilla. Tanto el hombre de ciencia como el hombre de la calle participan del ser. Sólo hay ser. Este contradiscurso rinde sus frutos cuando la filosofía descubre que el ser constituye el punto inamovible que se ha buscado y que, paradójicamente, no necesita buscarse. El ser es la primera y más segura de las posesiones del hombre.

Concluye Nicol diciendo que "el ser es el principio de todos los principios..., hemos encontrado, pues, el terreno firme que la filosofía ha requerido siempre" 41. Desde este punto de vista, puede decirse que la filosofía ahora experimenta un eminente vuelco hacia las cosas mismas. La investigación de la verdad cuenta ahora con una nueva pauta de partida; decimos nueva, no porque no la haya habido, sino porque la filosofía no la había reconocido, y por lo mismo no había trabajado sobre esta plataforma. Repetimos, junto con Nicol, el ser es la primera y más segura de nuestras posesiones. Podría decirse que la nueva ruta de la metafísica, desde el punto de vista de nuestro autor, comienza reconociendo que el ser no es un problema sino un dato. En torno a esto el autor comenta:

...el problema del ser y el tiempo proviene de una incomprensión del fenómeno. Así empieza y así termina la tradición metafísica.

La nueva vía se inicia declarando que el Ser no es problema, sino dato. Su captación no requiere ningún arte metodológico. 42

En suma, el contradiscurso enarbolado por Eduardo Nicol lleva a la filosofía hacia la recuperación de la visibilidad del ser. Esta travesía ha tenido que remar a contracorriente restituyendo, en primer lugar, el tiempo al ser, reconociendo en el dinamismo de la realidad el horizonte de visibilidad precisamente del ser. Esta evidencia adquiere un lugar preeminente, toda vez que es el punto de partida de todo conocimiento, sea vulgar o científico. La idea de razón, en nuestro autor, está matizada por la humildad y precisa siempre el concurso de las diferentes facultades psicológicas y de sensibilidad, amén de que precisa también el concurso del otro ${ }^{43}$; de

\footnotetext{
40 Para un estudio más exhaustivo en torno a la nueva confección del método o nuevo discurso del Método a partir de Nicol, Cfr. González, Roberto (2010A) pp. 169ss.

41 Nicol (2008), p. 126.

$42 \mathrm{Nicol}$ (2001B), p. 160. El subrayado es nuestro.

43 En este estudio se ha prescindido de la tematización del concepto de la otredad en virtud de que no constituye precisamente el tema del presente. La otredad, en Nicol, viene implícita en la novedosa concepción que el autor logra en torno a la noción de expresión. Esta noción aparece desde la Psicología de las situaciones vitales (1941), y logra una definición monumental en la Metafísica de la expresión (1957). En torno a la riqueza del concepto de expresión en Nicol puede consultarse: Nicol (2008), passim; Horneffer, (1990), pp. 79-85; Rush González, (2002), p. 37ss
} 
hecho, la evidencia del ser se adquiere mediante el concurso precisamente del otro sujeto. Así pues, este contradiscurso, ha tenido que mesurar a la razón haciéndola entrar en el claro de un concierto de capacidades epistémicas, reconociendo finalmente que el ser humano no puede desarticularse o fragmentarse. Podría decirse que la unidad del ser es garantía a un mismo tiempo del conocimiento y de , así la unidad del hombre.

\section{Referencias bibliográficas}

Aristóteles (2002): Metafísica, Madrid, Biblioteca Clásica Gredos.

Descartes, R. (2001): Discurso del método, Madrid, Editorial Edaf.

GonzÁlez, J., CAStary, V., y Mora, A. (coords.) (1998): Eduardo Nicol. La filosofia como razón simbólica. Barcelona, Huellas del conocimiento, Revista Anthropos, extraordinaria 3,1998.

GonzÁlez, J. y SAgols, L., (eds.). (1990): El ser y la expresión. Homenaje a Eduardo Nicol, México, Universidad Nacional Autónoma de México.

GoNZÁLEZ, R. (2010A): Estructura de la ciencia y posibilidad del conocimiento a partir de Eduardo Nicol, México, Universidad Autónoma del Estado de México GonZÁLEZ, R. (2010B): "El absoluto ausente. Una nota marginal en la ontología de Eduardo Nicol" en, Horneffer (coord.), Eduardo Nicol (1907-2007), México, UNAM.

GonZÁLEZ, R.A. (coord.). (2011): Escorzos de ontología contemporánea: Martin Heidegger, Gilles Deleuze, Eduardo Nicol, México, Ed. Torres y Asociados.

GonZÁLEZ, R. (2002): Retorno a la metafisica, en torno a los límites del logos ante el ser. Eduardo Nicol, México, Universidad Autónoma del Estado de México.

Heidegger, M. (2001): El ser y el tiempo, México, Fondo de Cultura Económica. Horneffer, R. (2000) Eduardo Nicol, Semblanza, México, Colegio de Jalisco. HornefFer, R. (1990) “Metafísica y expresión”, en, González, J. y Sagols, L. (eds.) (1990).

Nicol, E. (1989): Psicología de la situaciones vitales, México, Fondo de Cultura Económica.

Nicol, E. (2001B): Los principios de la ciencia, México, Fondo de Cultura Económica.

Nicol, E. (2008): Metafísica de la expresión, nueva versión, México, Fondo de Cultura Económica.

Nicol, E. (2003): La idea del hombre, nueva versión, México, Fondo de Cultura Económica.

Nicol, E. (1981): La agonía de Proteo, México, Universidad Nacional Autónoma de México. 
Nicol, E. (2001B): Crítica de la razón simbólica. La revolución en la filosofia, México, Fondo de Cultura Económica.

Nicol, E. (1998): El problema de la filosofía hispánica, México, Fondo de Cultura Económica.

Nicol, E. (1990): Ideas de vario linaje, México, Universidad Nacional Autónoma de México.

PARMÉnides (1981): Parménides, Zenón y Meliso, (Escuela de Elea). Versión castellana de José Antonio Míguez, Bs. As. Aguilar. Los fragmentos aparecen en las pp. 45-57.

PARMÉNIDES (2008): Los filósofos presocráticos I, versión castellana de Conrado Eggers Lan y Victoria E. Julia, Madrid, Biblioteca Clásica Gredos, 2008. Los fragmentos aparecen en las pp. 474-482.

Platón (1999): Cratilo, en, “ Diálogos” T. II, Madrid, Biblioteca Clásica Gredos, 1999.

Platón (1997): Timeo, en, "Diálogos" T. VI, Madrid, Biblioteca Clásica Gredos.

Roberto Andrés González

Facultad de Humanidades

Universidad Autónoma del Estado de México

rushlogo@yahoo.com.mx 